\title{
ZONAS (EIXOS) CONDUTIVAS EM ROCHAS CRISTALINAS NA REGIÃO DE IRAUÇUBA, NORTE DO ESTADO DO CEARÁ, BRASIL
}

\author{
José Alberto Ribeiro ${ }^{1}$ \\ Fernando A. C. Feitosa ${ }^{1}$ \\ José Farias de Oliveira ${ }^{1}$ \\ Oderson Antonio de Souza Filho ${ }^{1}$ \\ Edilton Carneiro Feitosa ${ }^{2}$
}

\section{RESUMO \\ No Projeto Otimização de Metodologias de Prospecção de Água Subterrânea em} Rochas Cristalinas, em desenvolvimento pelo Serviço Geológico do Brasil - CPRM, na porção norte do estado do Ceará, foram realizados levantamentos de geofísica terrestre (eletrorresistividade) e de aerogeofísica. $\mathrm{Na}$ interpretação dos caminhamentos elétricos, Ribeiro et al. (2001) identificaram um comportamento distinto entre os caminhamentos realizados na direção W-E e os realizados na direção N-S. Nos caminhamentos na direção W-E o comportamento elétrico configura uma acentuada alternância de zonas de maior e menor resistividades, enquanto que nos caminhamentos de direção N-S essa alternância não é tão evidente. Muitas vezes, como no caso da localidade Carnaubinha, o caminhamento $\mathrm{N}$-S caracterizou um comportamento homogêneo condutivo ao longo dessa direção, sugerindo que essas zonas estão orientadas predominantemente na direção N-S. Em levantamento aerogeofísico realizado pela LASA (2001) em uma porção da área do Projeto, o mapa de condutividade aparente na freqüência de $4.500 \mathrm{~Hz}$ mostrou a existência de vários eixos condutivos na direção evidenciada pelo método elétrico terrestre utilizado. Entretanto, feições lineares na direção N-S não são comumente destacadas nas imagens de sensores remotos da área.

\begin{abstract}
Ground geophysics (eletroresistivity) and airborne geophysics were executed at the north portion of the state of Ceará, Brazil being part of the institutional project of CPRM Geological Survey of Brazil "Optimization of Methodologies of Groundwater Research in Cristalline Terrains". In the interpretation of the ground survey, Ribeiro et ali (2001) identified a distinct behaviour waking along lines of $W-E$ and N-S direction. Along lines of $W-E$ direction, apparent resistivity values show pronounced alternate zones (axes) of higher and lower resistivity, while along $\mathrm{N}$-S lines, that zone alternation is not so evident. In many sites, as the locality of Carnaubinha, the N-S survey characterized a conductive behaviour along that direction suggesting that those zones are predominantly oriented $\mathrm{N}-\mathrm{S}$. The airborne survey carried out by LASA (2001) in part of the pilot-area, produced an apparent conductivity map at $4.500 \mathrm{~Hz}$ frequency which showed the existence of several conductivity axes in the same direction pointed out by the ground electric method. However, N-S lines features are not commonly enhanced in remote sensing images for the area.
\end{abstract}

Palavras-chave: Geofísica, eletrorresistividade, água subterrânea.

\section{INTRODUÇÃO}

No estado do Ceará predominam, em

$75 \%$ da área, rochas cristalinas com baixa vocação hidrogeológica, onde se buscam conhecimentos que favoreçam a localização das águas subterrâneas em meios

\footnotetext{
${ }^{1}$ Geólogos do Serviço Geológico do Brasil - CPRM - Residência de Fortaleza - Av. Santos Dumont, 7700 2ªndar - Fone (085) 265.1288 - CEP: 60.190-800 - Fortaleza-CE - e-mail: ribeiroja@yahoo.com.br, ffeitosa@secrel.com.br

${ }^{2}$ Hidrogeólogo da Agência Nacional de Águas - Fone (061) 445.5288 - CEP: 70.610-200 - Brasília -DF - e-mail: ediltonf@yahoo.com.br
} 
fraturados. A CPRM - Serviço Geológico do Brasil desenvolve estudos que visam a evolução do conhecimento da ocorrência da água subterrânea em meios anisotrópicos através do Projeto Otimização de Metodologias de Prospecção de Água Subterrânea em Rochas Cristalinas, em convênio de cooperação técnica entre o Canadá e Brasil, firmado através do GSC Geological Survey of Canada e da CPRM com o apoio financeiro da CIDA - Canadian International Development Agency. Essa cooperação visa primordialmente a transferência de tecnologia, na forma de treinamentos, capacitação e importação de tecnologias ainda não disponíveis no país para auxiliar no desenvolvimento dos trabalhos. O convênio abrange outras áreas de pesquisa no estado de Pernambuco e Rio Grande do Norte. Na área do Ceará, região de Irauçuba, além do mapeamento geológico, inventário de pontos d’água e qualidade das águas subterrâneas, foram realizados estudos de geofísica terrestre, método de eletrorresistividade com mais de $20 \mathrm{~km}$ de caminhamentos elétricos e levantamento aerogefísico usando métodos eletromagnéticos em uma porção da área (Bloco Juá) do Projeto com aproximadamente $154 \mathrm{~km}^{2}$.

\section{ÁREA DE TRABALHO}

$A$ área de trabalho abrange a Folha Irauçuba (SA.24-Y-D-V), localizada a 160 $\mathrm{km}$ de Fortaleza, delimitada pelos meridianos $39^{\circ} 30^{\prime}$ e $40^{\circ} 00^{\prime} \mathrm{W}$ e pelos paralelos $3^{\circ} 30^{\prime}$ e $4^{\circ} 00^{\prime} \mathrm{S}$ (figura 1). Engloba total e/ou parcialmente os municípios de Irauçuba, Itapagé, Itapipoca, Miraíma, Sobral, Tejuçuoca e Uruburetama, com área de $3.025 \mathrm{~km}^{2}$. O acesso é feito a partir de Fortaleza através da rodovia federal BR-222, cortando toda a área na direção aproximadamente leste-oeste. Em seu extremo noroeste é servida pela rede ferroviária federal (RFFSA) no trecho que liga as cidades de Itapipoca e Miraíma.

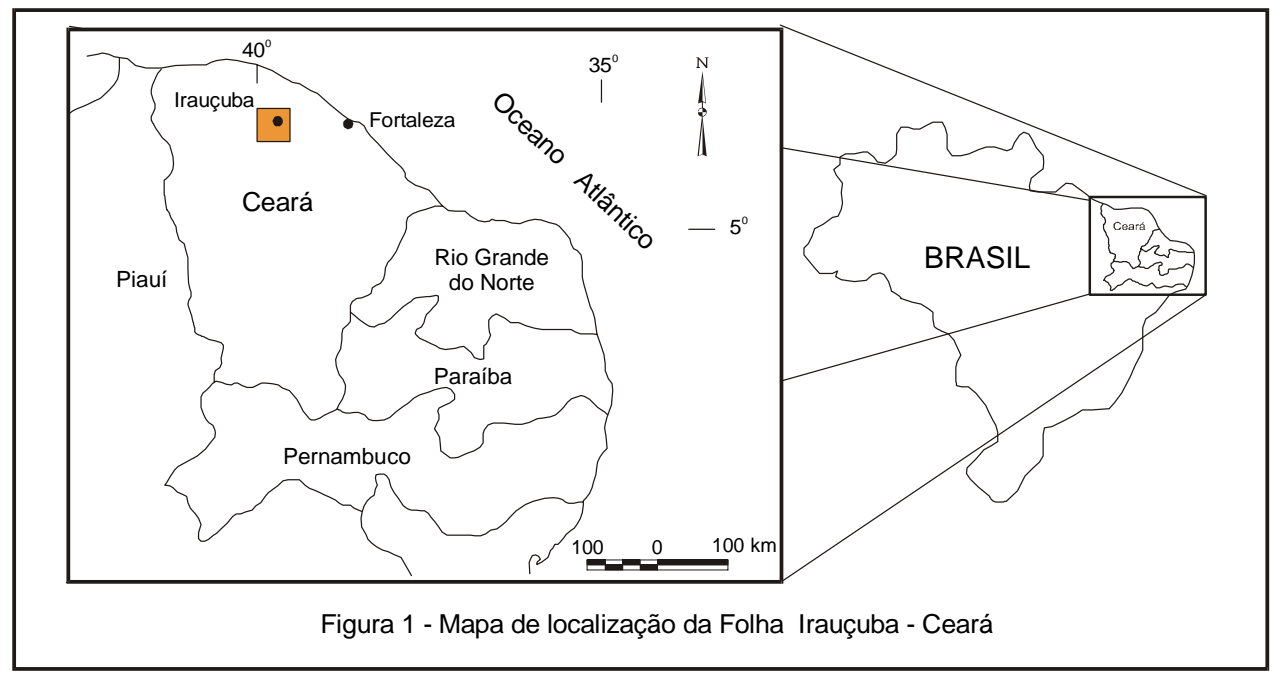

\section{ASPECTOS GEOAMBIENTAIS}

A geologia da Folha Irauçuba segundo SOUZA FILHO, 1999, é constituída por rochas do Pré-cambriano e depósitos aluviais. No âmbito das rochas précambrianas a unidade mais antiga é formada por rochas metamórficas de alto grau, predominando gnaisses migmatizados e metabasitos. A unidade seguinte constitui uma seqüência supracrustal essencialmente paraderivada, correlacionável ao Complexo Ceará, composta por gnaisses, xistos, quartzitos e metacarbonatos. Intrusivos nas seqüências descritas anteriormente, ocorrem corpos de dimensões variadas de rochas plutônicas granulares, deformadas ou não, de composição granodiorítica a granítica e diques básicos mesozóicos. Como representantes cenozóicos existem delgadas e esparsas coberturas sedimentares residuais e/ou transportadas, dominantemente areno-conglomeráticas, e depósitos aluvionares recentes. As feições geomorfológicas e seu modelado são representados na folha por depressões periféricas e interplanálticas submetidas a processos de pediplanização (depressões sertanejas) e pelos maciços residuais dissecados em formas de colinas e cristas. 
A área está inserida no denominado "Polígono das Secas", com índice de probabilidade de secas na faixa de 80 a $100 \%$. Apresenta três tipos de climas regionais, do mais seco ao mais úmido, devido à elevada compartimentação dos fatores geográficos que ocorrem para criar espaços climáticos altamente diferenciados. O clima úmido a subúmido ocorre na serra de Uruburetama, com temperatura média anual de $24^{\circ} \mathrm{C}$ e precipitação entre 1.200 $1.500 \mathrm{~mm}$. Nas encostas de toda a serra de Uruburetama, o clima subúmido predomina com precipitações anuais entre 800-1.200 $\mathrm{mm}$ e temperatura média de $28^{\circ} \mathrm{C}$. A porção sul da Folha Irauçuba, denominada de zona de sombra da serra de Uruburetama é caracterizada por um clima semi-árido, com precipitações anuais inferiores a $800 \mathrm{~mm}$ e temperatura média de $30{ }^{\circ} \mathrm{C}$. A rede hidrográfica local é representada pelos rios Caxitoré, Aracatiaçu, Itapagé, Missi, Livramento e Riachão, que fluem somente durante a época das chuvas. O padrão de drenagem dominante é o dendrítico, controlado por fatores estruturais. A vegetação predominante na maior parte da área é representada pela caatinga xerofítica de médio porte e tipo arbustiva-arbórea.

\section{DISCUSSÃO}

\section{Geofísica Terrestre}

Nos trabalhos de geofísica terrestre, método de eletrorresistivade, realizados na área em estudo, Ribeiro et al. (2001) selecionaram cinco poços, considerados de alta produção, com vazões variando de 5,5 a $15,0 \mathrm{~m}^{3} / \mathrm{h}$, para servirem como referência na execução dos trabalhos, cujo objetivo era verificar se existia um comportamento elétrico padrão associado à alta produtividade. Além desses poços investigados os trabalhos de geofísica terrestre prosseguiram em mais quatro localidades (poços), porém de vazões reduzidas. $\mathrm{Na}$ tabela a seguir estão relacionados todos os poços investigados.

\begin{tabular}{|c|c|c|c|c|c|}
\hline No & $\begin{array}{c}\text { Coordenadas } \\
\text { (UTM) }\end{array}$ & Local & Município & $\begin{array}{c}\text { Teste de pro- } \\
\text { dução }\left(\mathbf{m}^{\mathbf{3}} \mathbf{/ h}\right)\end{array}$ & $\begin{array}{c}\text { Caminhamento } \\
\text { Elétrico }(\mathbf{m})\end{array}$ \\
\hline 01 & $443.942 / 9.567 .278$ & Logradouro & Tejuçuoca & 8,00 & 2.000 \\
\hline 02 & $402.876 / 9.586 .543$ & Costa & Irauçuba & 5,50 & 2.060 \\
\hline 03 & $398.025 / 9.586 .436$ & Fumo & Irauçuba & 8,00 & 3.540 \\
\hline 04 & $419.560 / 9.589 .902$ & Barreiras (2) & Irauçuba & 0,43 & 2.000 \\
\hline 05 & $400.032 / 9.594 .471$ & Carnaubinha & Miraíma & 15,00 & 1980 \\
\hline 06 & $439.927 / 9.571 .450$ & Alegria & Tejuçuoca & 13,20 & 2.200 \\
\hline 07 & $416.739 / 9.586 .351$ & Pedra Ferrada & Irauçuba & & 1.840 \\
\hline 08 & $438.509 / 9.585 .839$ & Boa Vista & Itapagé & 1.980 \\
\hline 09 & $409.297 / 9.575 .355$ & Mandacaru (2) & Irauçuba & 4.280 \\
\hline \multicolumn{7}{|c|}{ T O T A L } \\
\hline
\end{tabular}

Foram aplicadas técnicas denominadas de exploração horizontal (Perfil de Resistividade) e adotado como dispositivo de medição das resistividades aparentes, o quadripolo linear simétrico AMNB de Schlumberger, tendo sido utilizado como equipamento um resistivímetro PER80/PROEL, fabricado pela DPM-Engenharia. Os caminhamentos elétricos (perfis) foram desenvolvidos 500 metros para cada lado a partir do poço considerado, geralmente nas direções norte, sul, oeste e leste. Foi utilizado um comprimento $A B$ de envio de corrente igual a 100 metros e um comprimento $\mathrm{MN}$ igual a 5 metros, sendo as estações de medição espaçadas de 20 metros.
$\mathrm{Na}$ interpretação dos caminhamentos elétricos, realizados nos poços produtivos, Ribeiro et al. (2001), mostraram a evidência de um comportamento distinto nos valores da resistividade aparente segundo as direções W-E e N-S, em quase todos os locais investigados. Os caminhamentos realizados na direção W-E mostram como característica, uma acentuada alternância de zonas (eixos) de maior e menor resistividade aparente. Já nos caminhamentos de direção $\mathrm{N}-\mathrm{S}$ essa característica é muito pouco acentuada, sugerindo a existência de zonas ou eixos condutivos orientados aproximadamente na direção norte-sul. Os resultados desses caminhamentos são apresentados a seguir, através da 
visualização gráfica e de comentários referentes a cada uma das localidades investigadas.

\section{- Logradouro}

Os resultados dos caminhamentos (Ribeiro et al., 2001) W-E e N-E da localidade Logradouro estão expressos na figura 2. Na direção W-E há uma alternância de zonas menos resistivas ladeadas por zonas mais resistivas e o poço associado a uma zona menos resistiva. Já na direção N$S$ o perfil apresenta um comportamento mais homogêneo e como ele corta transversalmente a parte central do perfil $\mathrm{W}$ $\mathrm{E}$, torna-se muito sugestivo que a zona condutiva aparentemente associada ao poço, tenha continuidade na direção do caminhamento, ou seja, N-S.

\section{- Costa}

Na localidade Costa, Ribeiro et al. (2001) realizaram 2.060 metros de caminhamento elétrico distribuídos em três perfis como apresentado na figura 3 . O perfil principal na direção W-E (na realidade $100^{\circ}$ $\mathrm{Az}$ ) esboçou a alternância de várias zonas mais e menos resistivas, sendo melhor definido as duas zonas da porção oeste. O perfil secundário W-E (440 metros) foi realizado 100 metros a norte do limite entre as duas zonas mais proeminentes (porção oeste) do perfil principal com o objetivo de verificar a sua continuidade para norte. O perfil N-S tem seu ponto inicial deslocado de 100 metros para norte em relação ao poço.

\section{- Fumo}

$\mathrm{Na}$ localidade Fumo foram realizados 3.540 metros de caminhamentos elétricos (Ribeiro et al., 2001), segmentados em seis perfis sempre orientados norte-sul ou oesteleste. Com a análise dos dois perfis principais, mostrados na figura 4, notadamente no perfil W-E, evidencia-se um comportamento mais resistivo do poço para oeste e menos resistivo para leste. No perfil transversal (N-S) o comportamento é mais heterogêneo alternando valores de maior e menor resistividade, sugerindo que o perfil foi realizado no limite entre as duas zonas principais do perfil anterior, uma vez que esse limite não deve ser muito retilíneo.
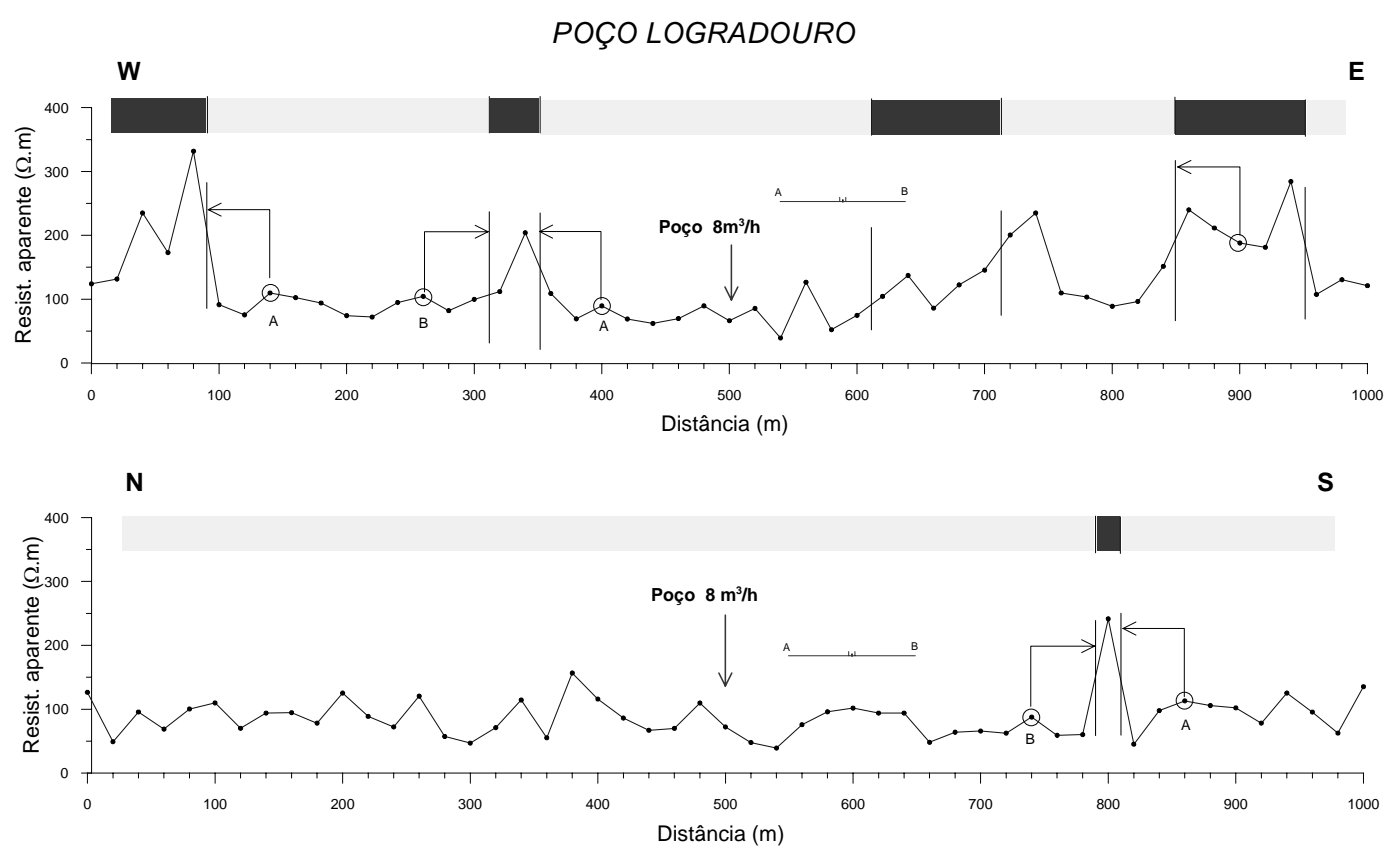

Figura 2 - Caminhamentos elétricos da localidade Logradouro (Ribeiro et al., 2001) 
POÇO COSTA
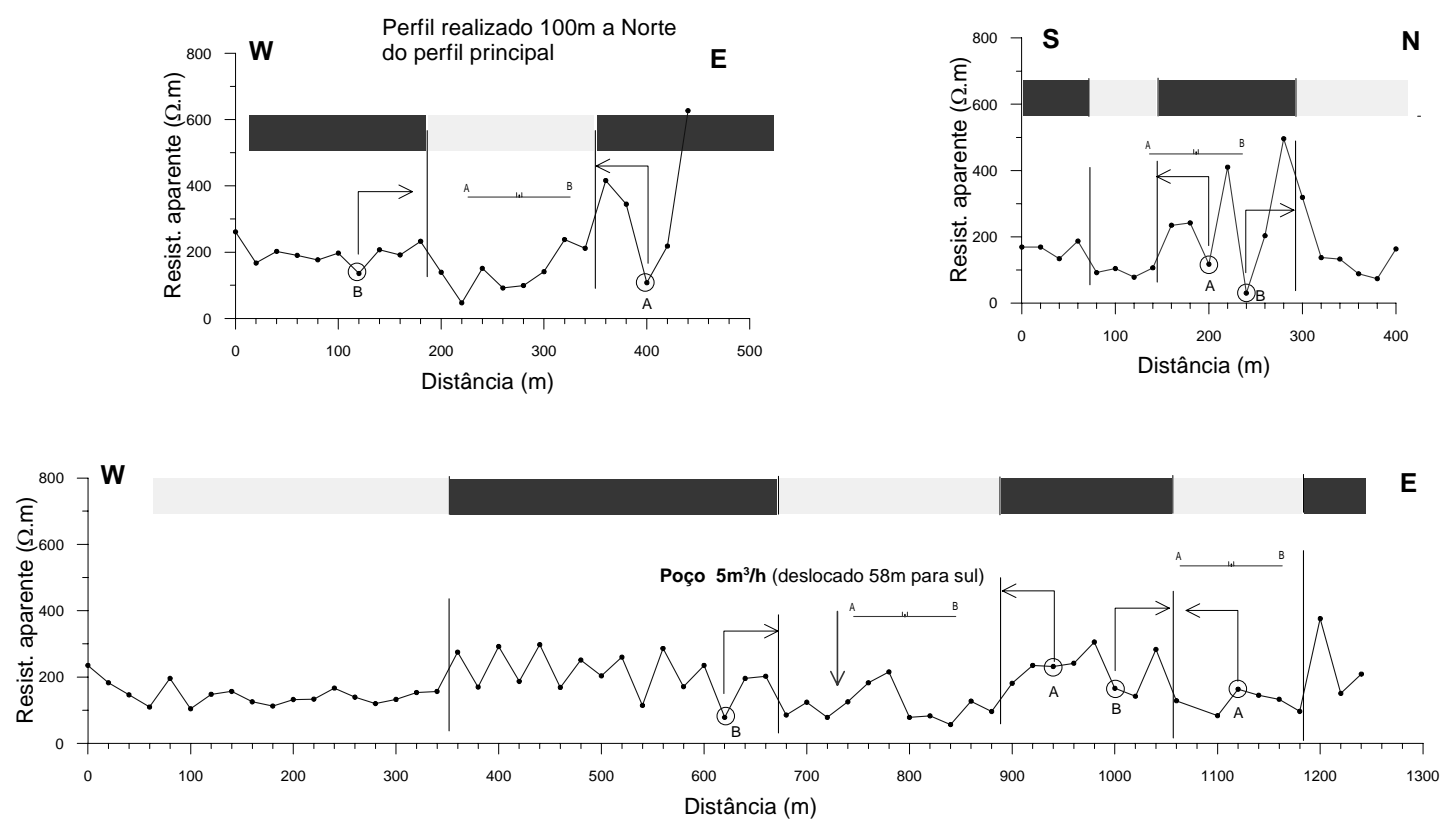

Figura 3 - Caminhamentos elétricos da localidade Costa (Ribeiro et al., 2001)
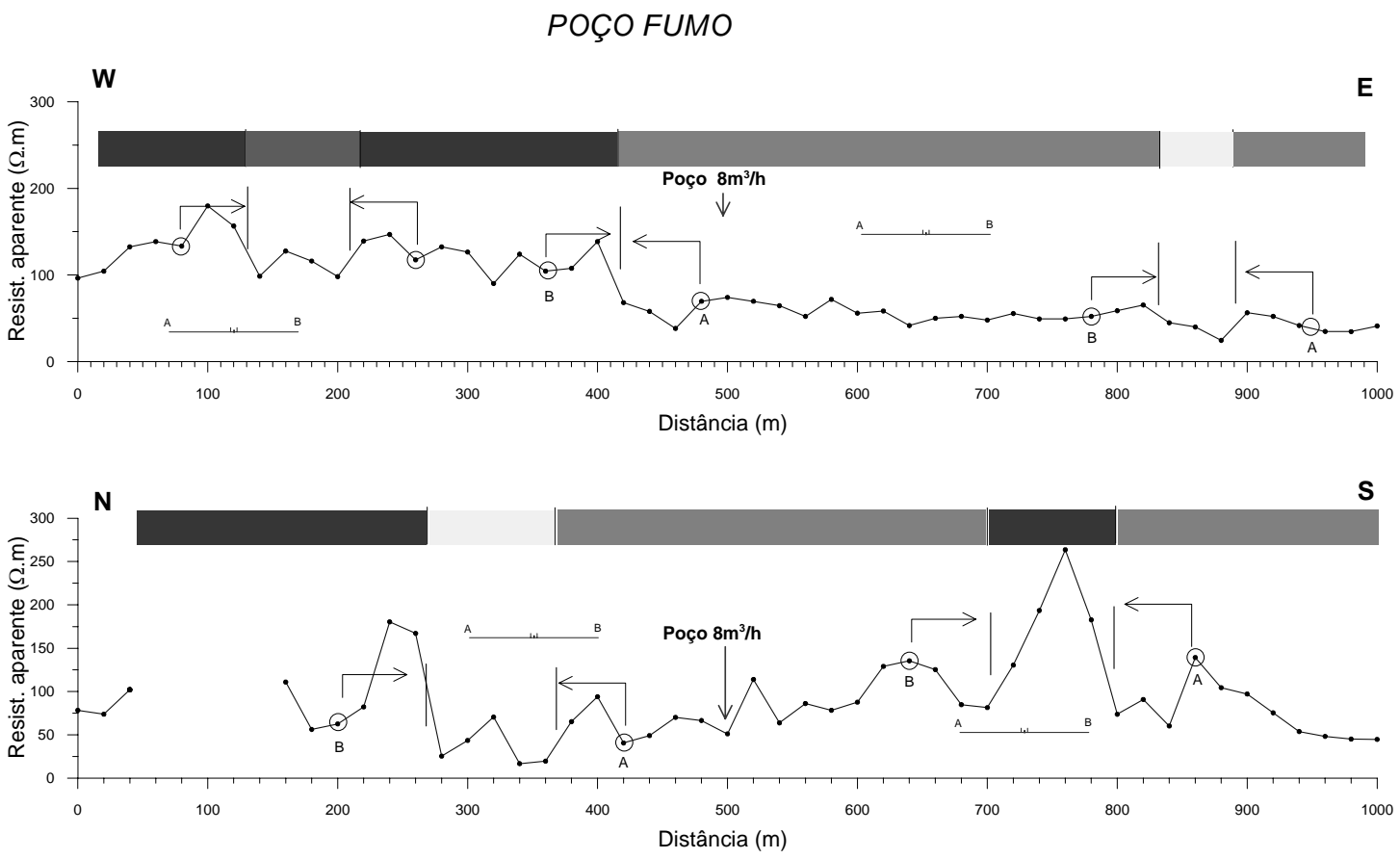

Figura 4 - Caminhamentos elétricos principais da localidade Fumo (Ribeiro et al., 2001)

Os perfis secundários (quatro) foram realizados a 200 metros do poço em cada uma das direções norte, sul, leste e oeste, cujos centros (dos perfis) coincidem com um dos perfis principais. No perfil a norte do poço (figura 5) os valores da resistividade são variados enquanto no perfil a sul nota-se com mais clareza uma zona de alta e outra de baixa resistividade. Nos perfis secundários de direção N-S (figura 6) os valores da resistividade são mais baixos, principalmente no perfil leste caracterizando uma zona de baixa resistividade relativa.

\section{- Barreiras}

$\mathrm{Na}$ localidade Barreias os caminhamentos elétricos (figura 7) mostraram um comportamento semelhante aos perfis principais da localidade Fumo, quando a direção W-E mostra uma zona 
mais resistiva a oeste e outra menos resistiva a leste. No caminhamento de direção N-S, como na localidade Fumo, também não ficaram bem caracterizadas essas zonas. Entretanto na localidade Fumo existe um poço considerado de boa produção, enquanto que em Barreiras 0 poço é pouco produtivo. Porém, os valores da resistividade aparente na localidade Barreiras são bem mais elevados.

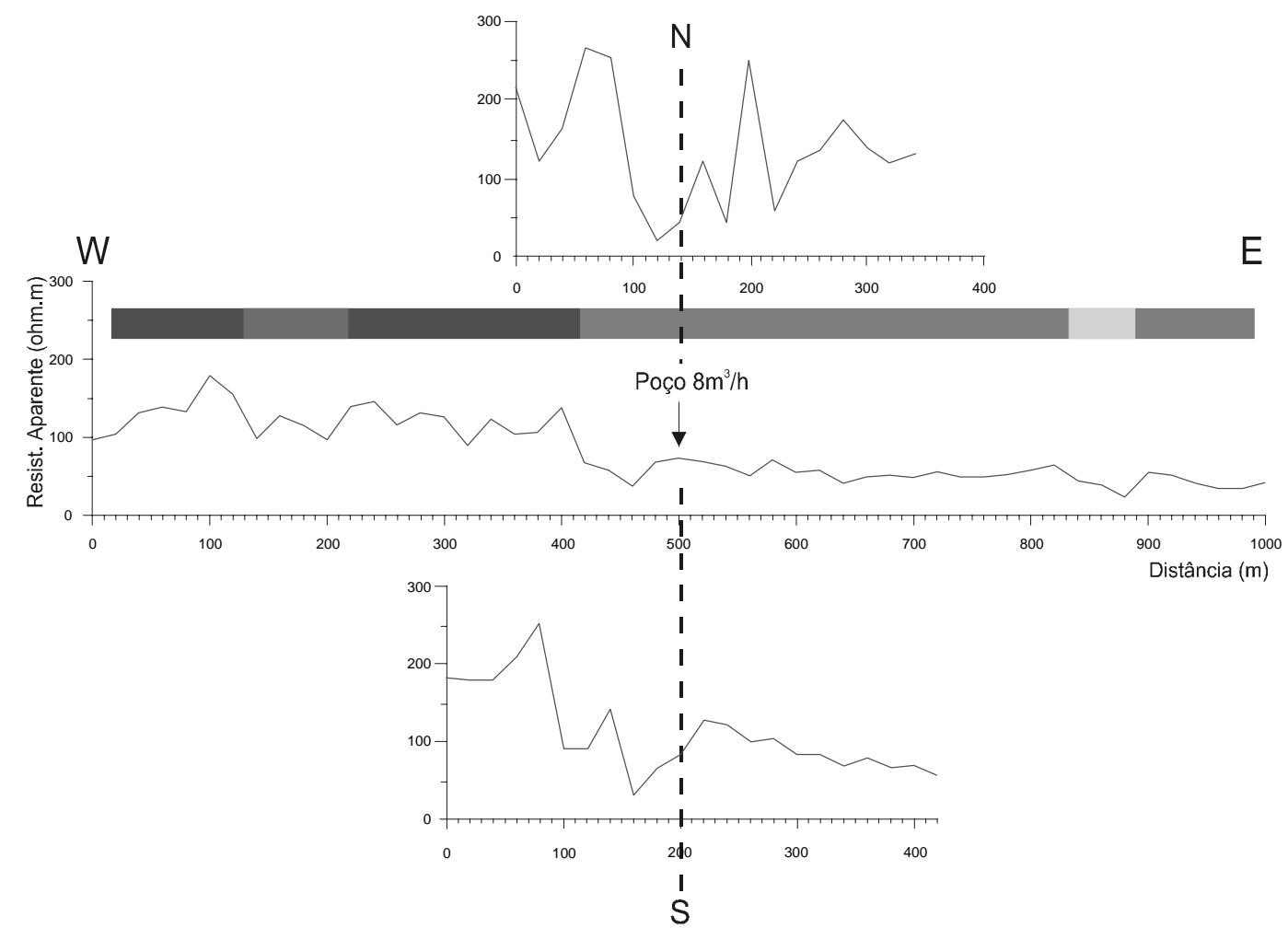

Figura 5 - Caminhamentos elétricos secundários de direção W-E da localidade Fumo

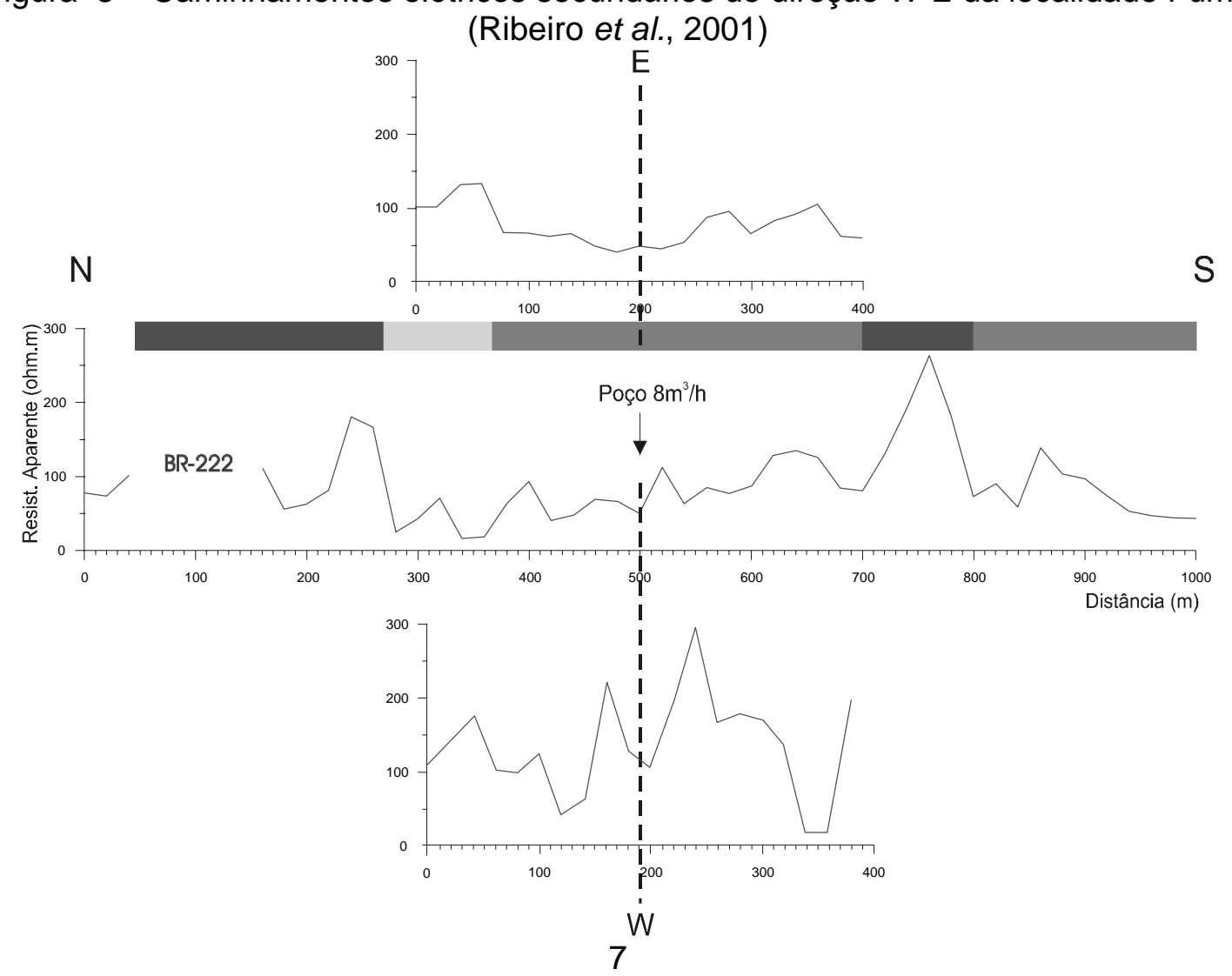

Figura 6 - Caminhamentos elétricos secundários de direção N-S da localidade Fumo (Ribeiro et al., 2001) 

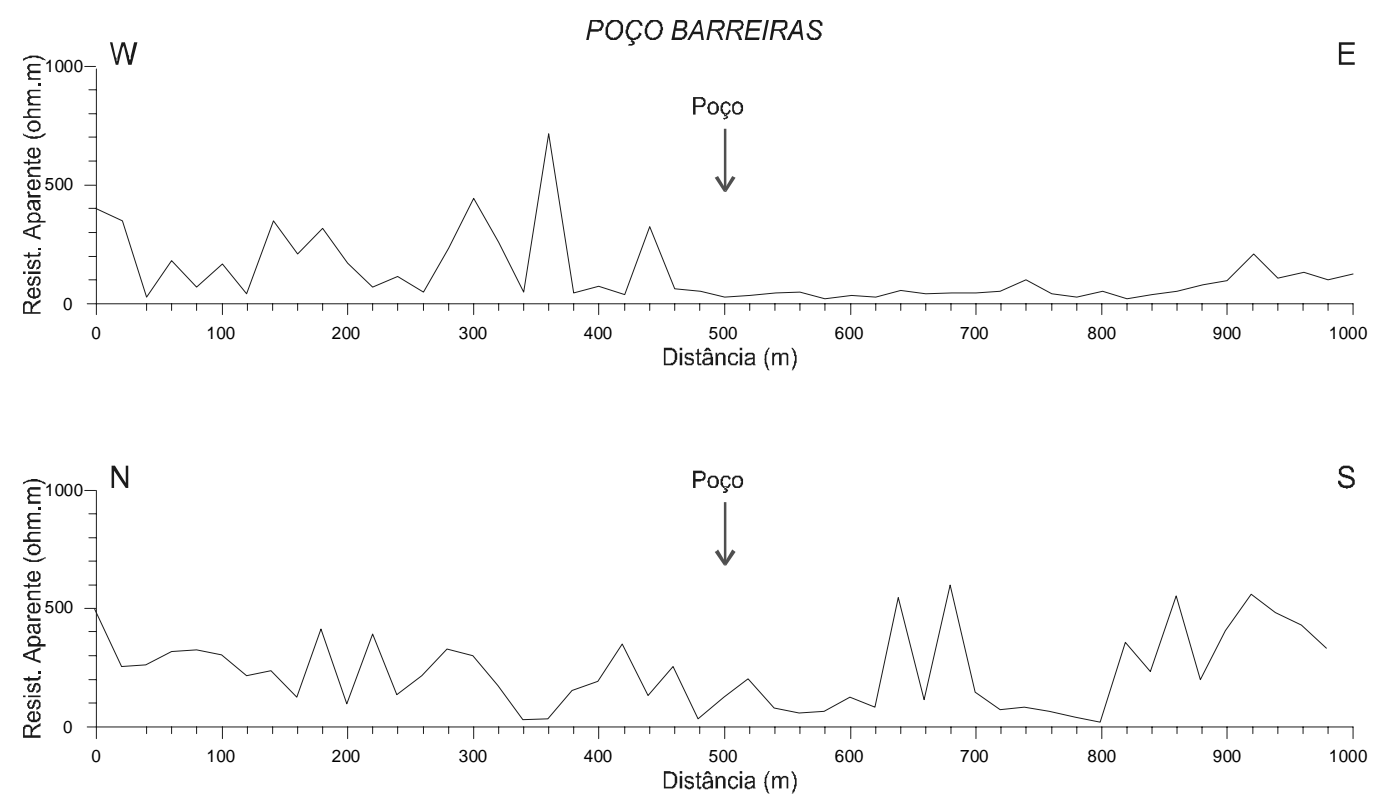

Figura 7 - Caminhamentos elétricos da localidade Barreiras

\section{- Carnaubinha}

Segundo Ribeiro et al. (2001) foram esses caminhamentos (figura 8) que caracterizaram melhor a continuidade N-S das zonas condutivas na área em estudo. No perfil $W$-E nota-se uma pronunciada zona condutiva ladeada por zonas resistivas, enquanto que o perfil $\mathrm{N}-\mathrm{S}$ apresenta-se extremamente homogêneo com valores muito baixos de resistividade aparente. Esse comportamento elétrico homogêneo e contínuo por todo o perfil mostra claramente que a zona condutiva refletida no perfil W-E e aparentemente associada ao poço está alinhada aproximadamente N-S. Outra informação importante que deve ser considerada como relevante é a produtividade do poço, a maior da região, pois pode haver uma relação direta entre a expressividade das zonas condutivas e produtividade de poços.

\section{- Alegria}

$\mathrm{Na}$ localidade Alegria (Ribeiro et al., 2001), os caminhamentos elétricos não obedeceram à sistemática N-S e W-E, sendo suas direções NW-SE e NE-SW, e talvez por isso apresentaram comportamento semelhante, conforme ilustrado na figura 9. São evidenciadas zonas resistivas, ladeadas por zonas menos resistivas, destacando-se uma zona central pronunciadamente resistiva. De acordo com gráfico NW-SE o poço foi locado na passagem de uma zona resistiva para condutiva, sugerindo que a locação mais apropriada deveria ser deslocada um pouco para leste.

\section{- Pedra Ferrada}

$\mathrm{Na}$ localidade Pedra Ferrada o caminhamento elétrico W-E (figura 10) mostra um comportamento mais homogêneo com moderada amplitude de variação nos valores de resistividade aparente, exceção do valor anômalo a 380 metros da origem oeste. O caminhamento N-S mostra uma tendência na redução dos valores da resistividade norte para sul. Nesse local o resultado da investigação geofísica não foi satisfatório quanto ao modelo evidenciado nas outras localidades. 

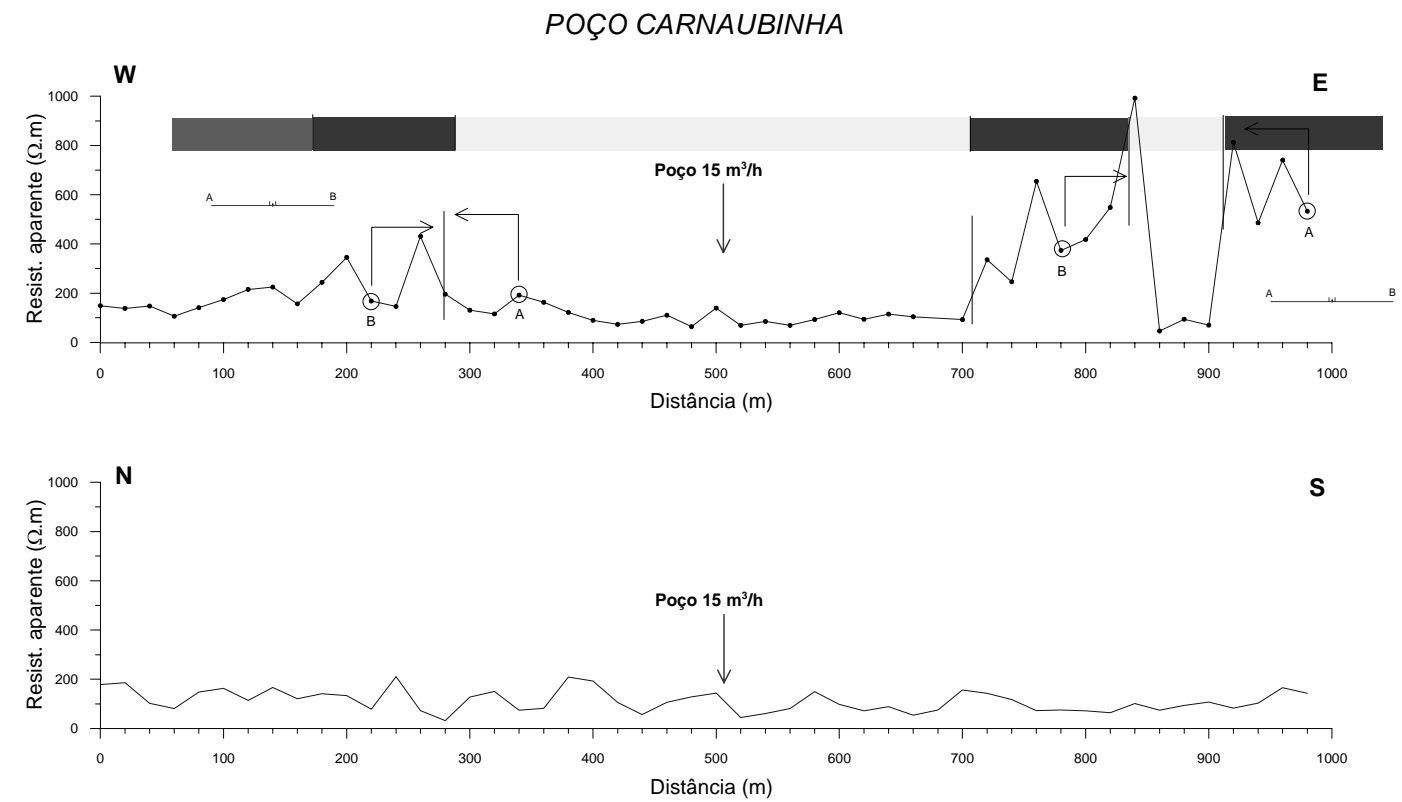

Figura 8 - Caminhamentos elétricos da localidade Carnaubinha (Ribeiro et al., 2001)

\section{POÇO ALEGRIA}
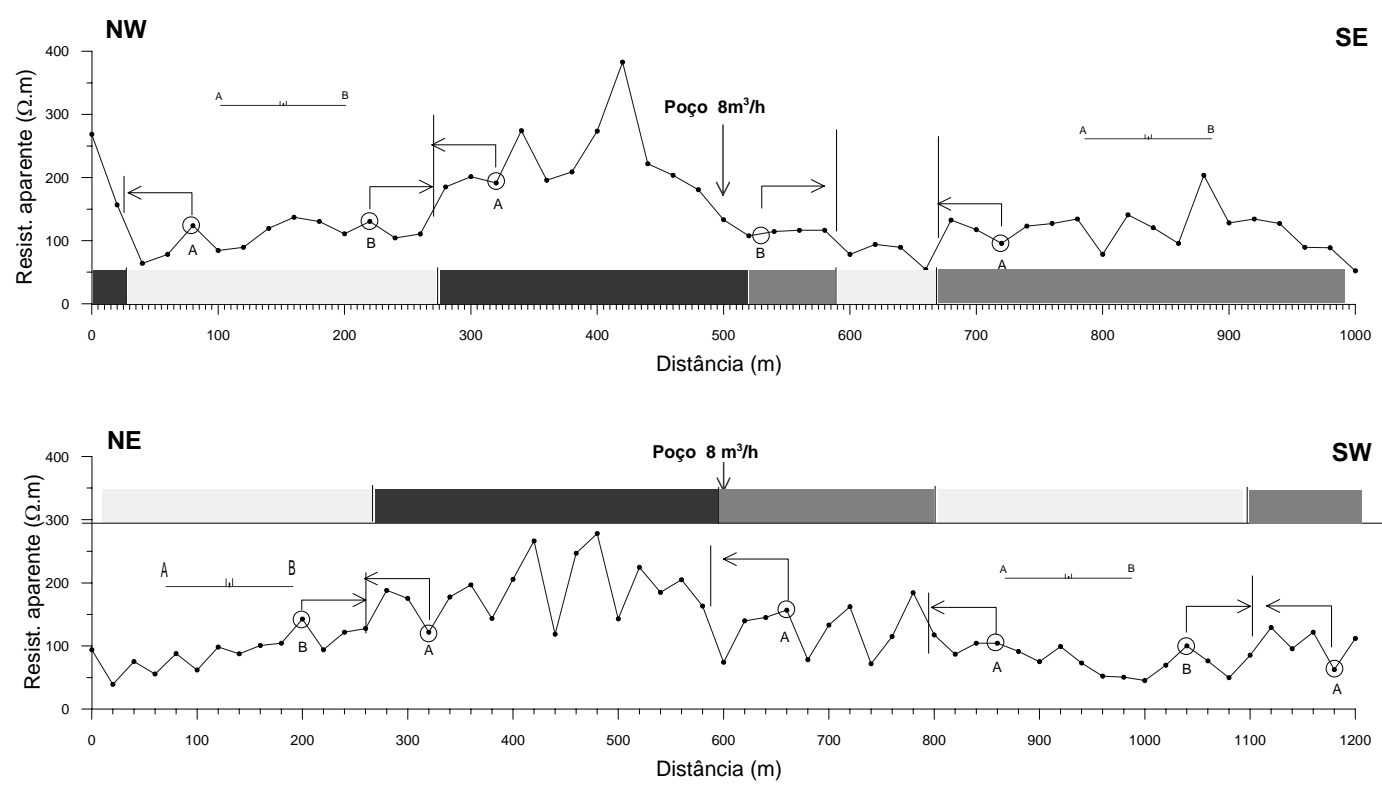

Figura 9 - Caminhamentos elétricos da localidade Alegria (Ribeiro et al,, 2001)

\section{- Boa Vista}

Na localidade Boa Vista (figura 11) os caminhamentos elétricos apresentaram um comportamento onde predominam valores elevados de resistividade. $\mathrm{Na}$ direção $\mathrm{W}-\mathrm{E}$ zonas resistivas melhor definidas enquanto na direção N-S mostra fortes oscilações nos valores da resistividade aparente, situados entre 162,70 e $2.291,47$ ohm.m.

\section{- Mandacaru}

$\mathrm{Na}$ localidade Mandacaru os caminhamentos elétricos (figura 12) tanto na direção W-E como N-S (três perfis) têm comportamentos semelhantes, mostrando pouca variação na amplitude da resistividade aparente com propensão a valores condutivos. Próximo à extremidade $E$ do caminhamento $W-E$ há uma tendência a valores relativamente mais resistivos. 

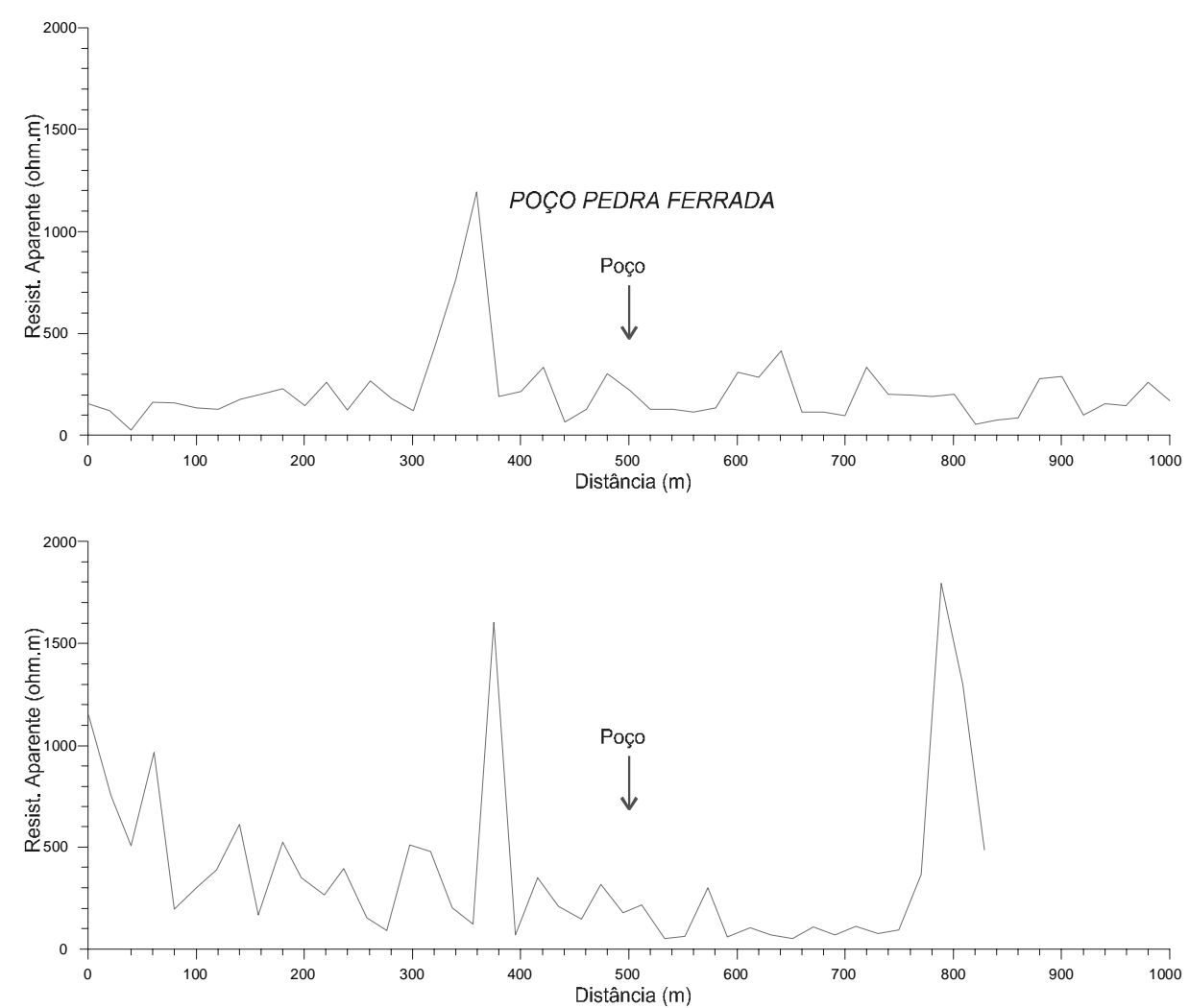

Figura 10 - Caminhamentos elétricos da localidade Pedra Ferrada
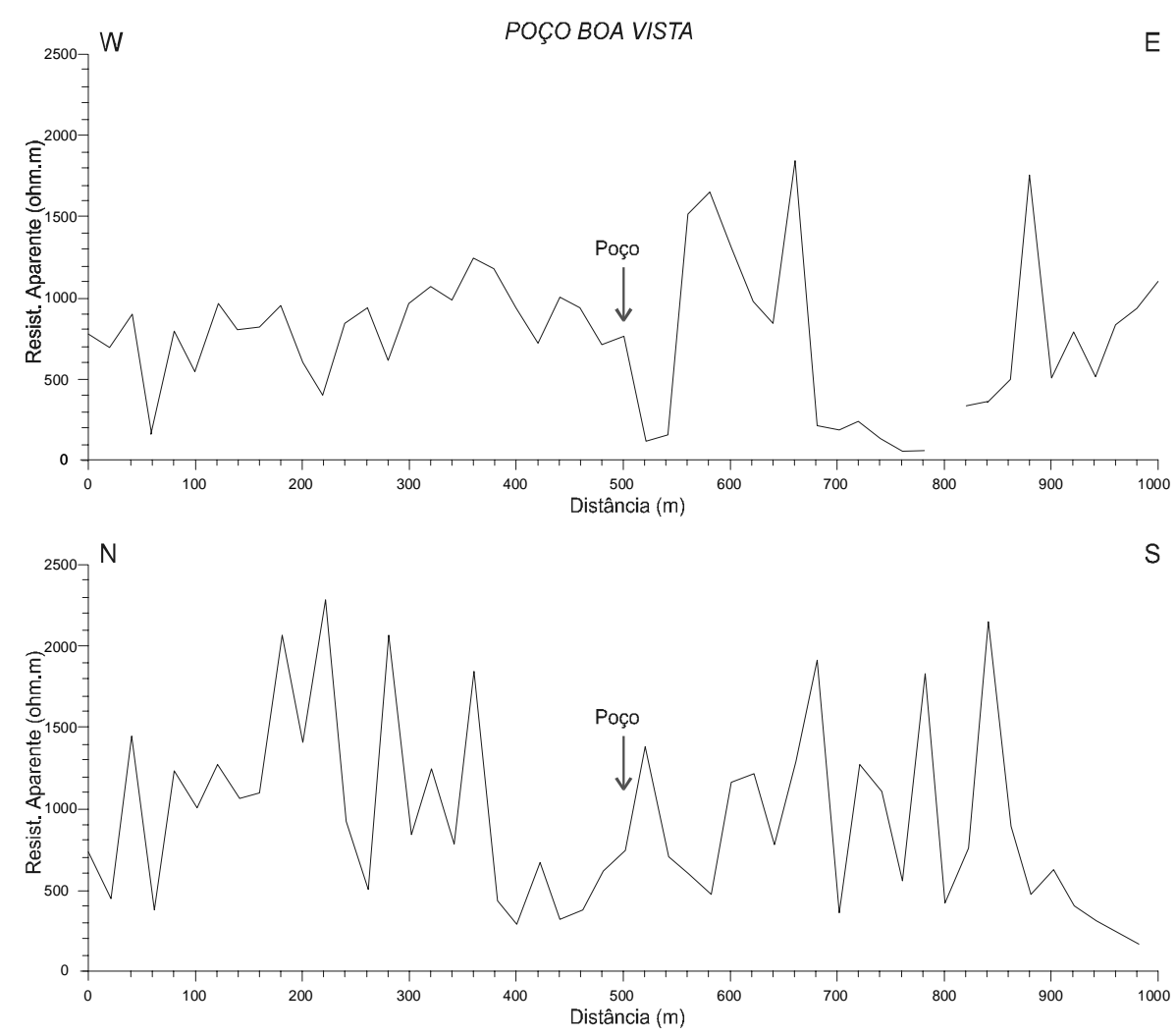

Figura 11 - Caminhamentos elétricos da localidade Boa Vista 


\section{Aerogeofísica}

O levantamento aerogeofísico foi executado em 2001 pela LASA Levantamentos Aerogeofísicos, na área de detalhe, Juá, com aproximadamente 154 $\mathrm{km}^{2}$ e não contempla os locais investigados pela geofísica terrestre, exceção da localidade Mandacaru. As linhas de vôo foram na direção $W$-E, espaçadas de 100 metros, e as linhas de controle na direção N-
S, espaçadas de 500 metros. Foram levantados no total $1.873 \mathrm{~km}$ de linhas.

Do levantamento aerogeofísico vamos nos reportar apenas ao mapa de condutividade aparente. O mapa apresentado foi gerado a partir do cálculo da freqüência média $(4.500 \mathrm{~Hz})$, coaxial (figura 13), na escala 1:20.000. A condutividade aparente foi calculada com base no modelo de pseudo-camada.
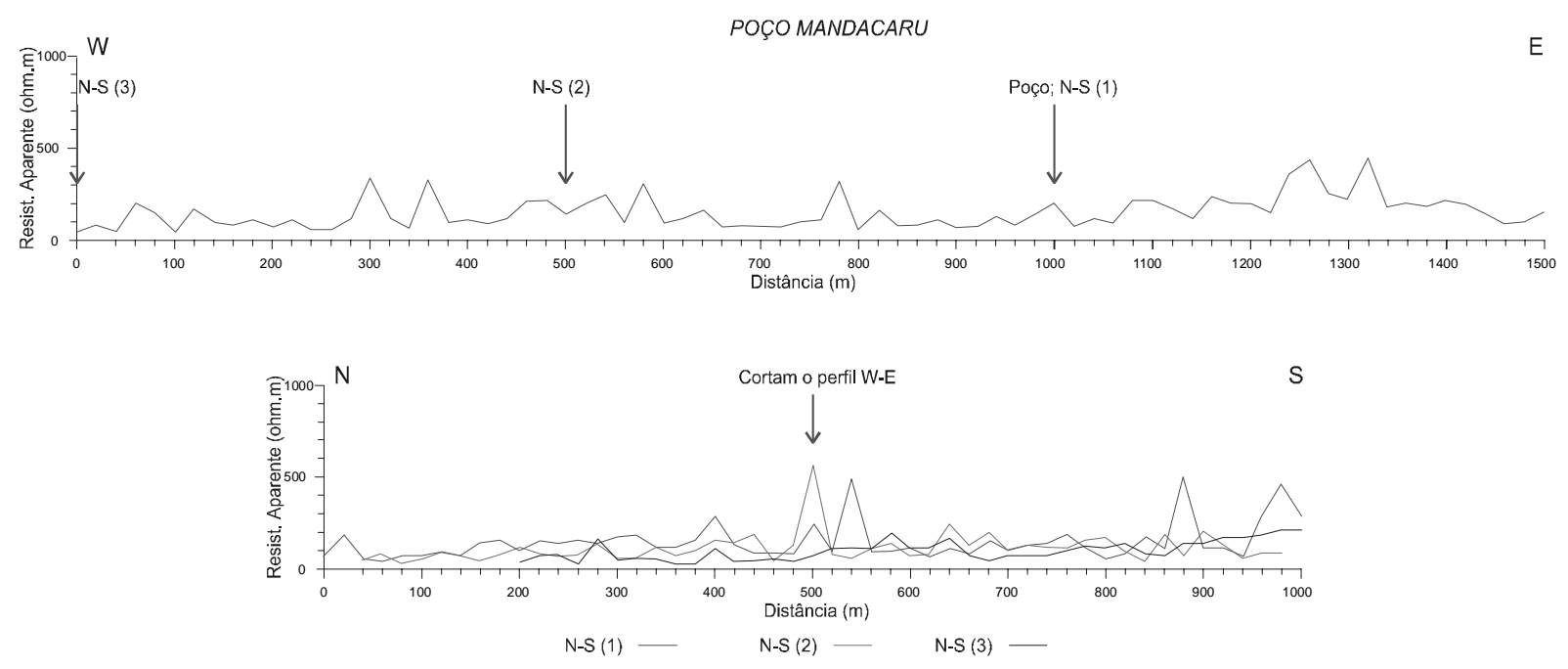

Figura 12 - Caminhamentos elétricos da localidade Mandacaru

Como se observa no mapa de condutividade aparente (figura 13), são várias feições lineares indicando "eixos de condutividade" com direção aproximadamente N-S, corroborando com a direção evidenciada pelo método elétrico. Muitas dessas feições (eixos condutivos) cortam indiscriminadamente seqüências litológicas diferentes. 


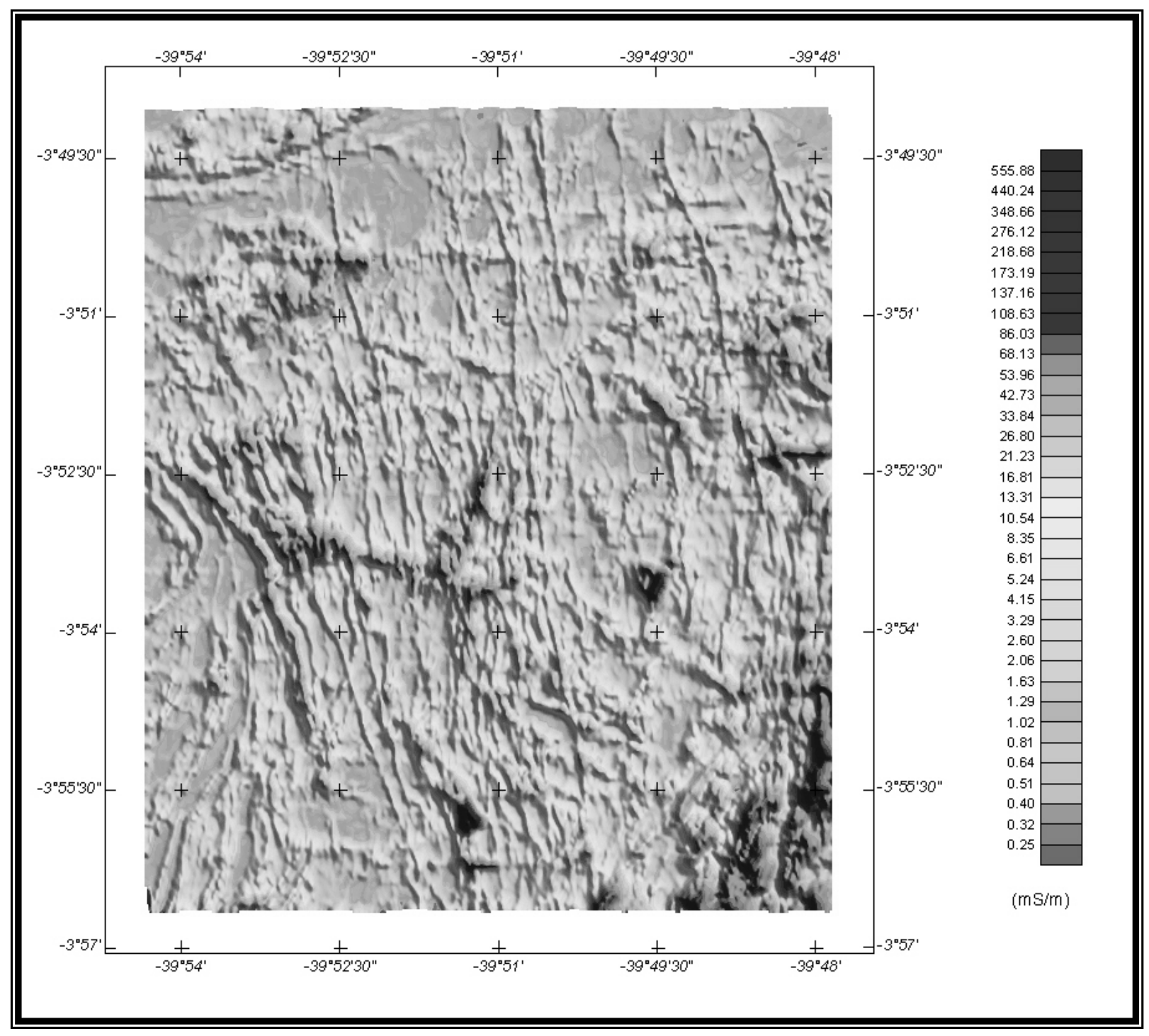

Figura 13 - Mapa Pseudo- lluminado da Condutividade Aparente $(4.500 \mathrm{~Hz})$ - Bloco Juá (Azimute da Fonte Luminosa: 45; Inclinação: $45^{\circ}$ )

\section{CONCLUSÕES}

A existência de alinhamentos de zonas condutivas na direção N-S, foi sugerida por Feitosa (1994) na região de Alagoinha-PE. Entretanto, esse autor questiona a possibilidade dessa disposição espacial ser aparente, como resultado da distribuição dos perfis de eletrorresistivade que priorizou a investigação dos fraturamentos N-S.

O fato é que esse alinhamento foi observado também na região de IrauçubaCE. É característico na maioria dos locais investigados com eletrorresistivade um padrão de comportamento distinto entre os caminhamentos elétricos de direção W-E e $N-S$. Nos de direção W-E a evidência de zonas alternadas de maior e menor resistividade aparente é melhor definida que na direção N-S. O melhor exemplo é o da localidade Carnaubinha (figura 8), onde no perfil W-E observa-se uma pronunciada zona condutiva ladeada por zonas resistivas, cuja continuidade é confirmada ao longo de todo o perfil N-S.

Outro fato interessante é que, no levantamento aerogeofísico (LASA, 2001) realizado em uma porção da área em estudo, bloco Juá, o mapa de condutividade aparente na freqüência de $4.500 \mathrm{~Hz}$ mostrou de forma bastante expressiva a existência de feições condutivas na direção evidenciada pelo método elétrico. Deve-se ressaltar, também, que nas áreas piloto levantadas pelo mesmo método nos estados do Rio Grande do Norte e Pernambuco os eixos condutivos também aparecem, embora, de forma mais discreta. 
Convém destacar que feições lineares na direção N-S não são comumente destacadas nas imagens de sensores remotos da área, e, portanto, ainda não existe uma explicação geológica consistente para justificar a existência dessas feições.

\section{REFERÊNCIAS}

FEITOSA, E. C. 1994. Alagoinha Caracterização de zonas fendilhadas no cristalino através do método geofísico de eletrorresistividade. LABHID - UFPE. 63 p. il. Relatório Inédito. Recife.

FEITOSA, F. A .C; SOUZA FILHO, O. A. de; VIEIRA, A. T.;VASCONCELOS, S. M. S 1998. Caracterização Hidrogeológica da Região de Irauçuba - CE - SIMPÓSIO
DE HIDROGEOLOGIA DO NORDESTE, ABAS, Anais, p. 35-46, il.

SOUZA FILHO, O. A. de, 1998. Geologia e Mapa de Previsão de Ocorrência de Água Subterrânea - Folha SA.24-Y-D-V Irauçuba, Ceará. Departamento de Geologia, Escola de Minas - UFOP. 99p. il. (Dissertação de Mestrado). Ouro Preto RIBEIRO, J. A; FEITOSA, F. A. C, FEITOSA, E. C; PEDROSA, P. de M. da C. 2001. Caracterização do Comportamento Elétrico em Rochas Cristalinas na Região de Irauçuba, Norte do Estado do Ceará, Brasil. In: IV SIMPÓSIO DE HIDROGEOLOGIA DO NORDESTE, ABAS, Anais, p. 225-233, il. Recife, 2001. 